\title{
Preparation of Interconnected Biomimetic Poly(vinylidene fluoride- co-chlorotrifluoroethylene) Hydrophobic Membrane by Tuning the Two-Stage Phase Inversion Process
}

\author{
Libing Zheng, ${ }^{\dagger, \ddagger, \S \odot}$ Jun Wang, ${ }^{*}, \dagger, \|$ Zhenjun $\mathrm{Wu}^{\perp}{ }^{\perp}$ Jie Li, ${ }^{\dagger}$ Yong Zhang, ${ }^{\dagger, \|}$ Min Yang, ${ }^{\dagger, \ddagger}$ \\ and Yuansong Wei*,+, \\ ${ }_{\dagger}^{\dagger}$ State Key Laboratory of Environmental Aquatic Chemistry, Research Center for Eco-Environmental Sciences, ${ }^{\dagger}$ Laboratory of Water \\ Pollution Control Technology, Research Center for Eco-Enviromental Sciences, and "Beijing Key Laboratory of Industrial \\ Wastewater Treatment and Resource Recovery, Research Center for Eco-Environmental Sciences, Chinese Academy of Sciences, \\ Beijing, 100085, China \\ ${ }^{\S}$ University of Chinese Academy of Sciences, Beijing, 100049, China \\ ${ }^{\perp}$ College of Chemical Engineering and Environment, Beijing Institute of Technology, Beijing, 100081, China
}

Supporting Information

ABSTRACT: A facile strategy was applied for poly(vinylidene fluoride-cochlorotrifluoroethylene) (PVDF-CTFE) hydrophobic membrane preparation by tuning the two-stage phase inversion process. The exposure stage was found to benefit the solid-liquid demixing process (gelation/crystallization) induced by the solvent evaporation and the subsequent phase inversion induced by immersion benefit the liquid-liquid demixing. It was confirmed that the electrospun nanostructure-like biomimetic surface and interconnected pore structure can be expected by controlling the exposure duration, and $300 \mathrm{~s}$ was considered as the inflection point of exposure duration for PVDF-CTFE membrane through which a tremendous variation would show. The micro/ nanohierarchical structure in the membrane surface owing to the crystallization of PVDF-CTFE copolymer was responsible for the improvement of membrane roughness and hydrophobicity. Meanwhile, the interconnected pore structure in both the surface and the cross-section, which were formed because of the crystallization process, offers more mass transfer passages and enhances the permeate flux. The membrane then showed excellent MD performance with high permeate flux, high salt rejection, and relatively high stability during a $48 \mathrm{~h}$ continuous DCMD operation, according to the morphology, pore structure, and properties, which can be a substitute for hydrophobic membrane application.

KEYWORDS: biomimetic membrane, interconnectivity, crystallization, two-stage phase inversion, exposure duration

\section{INTRODUCTION}

Membrane distillation (MD) is a promising membrane process in seawater desalination, water purification, and resource recovery processes which have been widely studied since the 1960s. ${ }^{1}$ It is a thermal-driven process, in which the membrane guarantees that only vapor/gas can transfer through the membrane., ${ }^{2,3}$ Thus, it can offer high separation efficiency especially in desalination application (theoretically 100\%). MD combined the traditional distillation and the membrane process, which enjoy numerous benefits in water treatment and desalination due to the low-energy requirement, low cost, and low-operational pressure. ${ }^{2,4,5}$ However, hydrophobic membranes with desirable structure and properties were the biggest obstacle for MD application because of the membrane wetting and fouling issues, low water productivity, and short lifespan, especially when speaking to MD industrial extension. $^{6-10}$
Inspired by the natural hydrophobic/superhydrophobic surface like lotus leaves, gecko feet, and rose petals, the preparation of hydrophobic membranes with a biomimetic surface has became a growing research topic in recent years. ${ }^{11-13}$ The hydrophobicity/superhydrophobicity surface is characterized by papillose and microgrooved structure with high roughness, where the microhierarchical and nanohierarchical morphologies offer a higher contact angle (CA) because of the air trapped in the "pockets" according to the Cassie-Baxter equation. ${ }^{12,14}$ Thus, tailoring the membrane interfacial morphology and surface pore structure with micro/ nanobump structure aiming to control the surface wettability has been widely investigated. $\mathrm{Li}$ et al. ${ }^{9}$ prepared dual-

Received: September 7, 2016

Accepted: November 9, 2016

Published: November 9, 2016 
biomimetic hierarchically polystyrene (PS) micro/nanofibrous membrane by electrospinning. The membrane exhibited a nanopillose, nanoporous, and microgrooved surface like lotus leaf, so it was superhydrophobic and presents excellent $\mathrm{MD}$ desalination performance (permeate flux of $104 \mathrm{~kg} / \mathrm{m}^{2} \cdot \mathrm{h}$ as $\Delta T$ was $50{ }^{\circ} \mathrm{C}$ ). Hydrophobic nanoparticles have also been applied for hydrophobic composite membranes preparation; the resultant membranes showed higher porosity and superhydrophobicity due to the microstructure formed by the doped nanoparticles. Thus, the membrane has excellent waterproofing property and breathability especially when electrospinning was applied. ${ }^{8,15-19}$ Photoinitiated polymerization-induced phase inversion was also used to generate a rough surface like rose petals in the membrane surface, and the resultant membrane showed parahydrophobicity with a high contact angle. ${ }^{11}$ To date, a diversified strategy like electrospinning, addition of hydrophobic nanoparticles, surface coating or cross-linking, and chemical vapor deposition was applied for biomimetic membrane preparation, tuning the surface with micro/nanohierarchical structure and an interconnected surface pore structure were the basic principles. $^{6,13,20-27}$

The surface pore structure also significantly influences the membrane selectivity. The pore structure with high interconnectivity guarantees high rejection with desired flux and vice versa. Meanwhile, the pores in cross-section, which act as the effective mass transfer passages, guarantee the membrane permeability as the pores were highly interconnected. Thus, the interconnectivity should be highlighted when evaluating the permeability of membranes. In recent years, preparation of membranes with interconnected pore structure has been another direction in membrane science. ${ }^{27-29}$ Recently, electrospinning technology has been used to fabricate hydrophobic membranes. The membranes prepared by electrospinning present interconnected pore structure due to the layer-bylayer accumulation of nanofibers and higher roughness because of the nanoarched structure in membrane surface, which has ideal structure and properties for $\mathrm{MD}$ applications and has shown excellent performance on MD process. ${ }^{6,30}$ However, the slow membrane formation rate, high voltage operation condition, and high investment confined its commercial applications. Phase inversion, a traditional membrane preparation technology, finds most applications especially in commercial process.

Four phase inversion processes including thermally-induced phase inversion (TIPS), vapor-induced phase inversion (VIPS), nonsolvent diffusion-induced phase inversion (DIPS) (also known as the immersion phase inversion), and evaporationinduced phase inversion (EIPS, also known as air casting) were commonly applied for polymeric membrane preparation. ${ }^{31,32}$ The solution was immersed in a nonsolvent coagulation bath after casting, and the immediate phase inversion was induced by the fast exchange of solvent and nonsolvent in the DIPS process. In the VIPS process, the nonsolvent vapor (commonly water) permeates to the casting solution induced the delayed phase inversion process. While the phase inversion can be induced by solvent evaporation or water vapor adsorption by solvent, the solid-liquid process happed in both processes and the phase inversion rate was slow in the EIPS process. Generally, membrane prepared by VIPS or EIPS showed particulate-packed interconnected structure due to the solidliquid demixing ( $\mathrm{S}-\mathrm{L}$ demixing) by polymer gelation or crystallization, while membrane prepared by DIPS showed typical asymmetric structure including a dense top layer, macrovoids layer, and sponge-like sublayer due to the instantaneous liquid-liquid demixing ( $\mathrm{L}-\mathrm{L}$ demixing). ${ }^{33,34}$ Controlling the gelation/crystallization of polymer by tuning membrane preparation condition or adding extra additives to acquire interconnected pore structure and hydrophobic surface has been widely investigated in hydrophobic membrane preparation. A two-stage phase inversion strategy by two coagulation baths with at least one soft nonsolvent (nonsolvent which has low interaction with solvent such as ethanol) has been applied for polymeric membrane preparation, through which the membrane morphology and pore structure were tuned by controlling the phase inversion rate. ${ }^{35,36}$

In this contribution, a two-stage phase inversion strategy combining EIPS and DIPS was applied to prepare poly(vinylidene fluoride-co-chlorotrifluoroethylene) (PVDF-CTFE) membrane, and the biomimetic membrane was prepared by the facile NIPS method for the first time by controlling the duration of two stages. The effect of the evaporation duration on membrane morphology, properties, and MD performance was investigated. Specifically, the effect of the first stage phase inversion induced by solvent evaporation on the subsequent phase inversion in coagulation bath was carefully characterized and analyzed to understand the membrane formation process. Membrane surface pore structure was carefully studied in terms of morphology, pore structure, roughness, and hydrophobicity to obtain a complete understanding of the phase inversion process during membrane formation by field emission scanning electron microscopy (FE-SEM), atomic force microscopy (AFM), and SEM image analysis. The overall pore structure and $\mathrm{MD}$ performance were also studied to evaluate the resultant membranes. In particular, the pore interconnectivity was highlighted as an important factor for membrane evaluation because it was highly related to the mass transfer in the membrane process. Clearly evidence showed that the exposure duration has a significant influence on the resultant membranes. An inflection point, an exposure time through which the radical change would appear, was clearly observed and confirmed by all characterizations. It was sure that the interconnected biomimetic membrane can be obtained by tuning the twostage phase inversion process, and the PVDF-CTFE membrane showed great potential for MD application.

\section{EXPERIMENTAL SECTION}

Materials. PVDF-CTFE (Solef 32008 with $M_{\mathrm{w}}=280000$, $\mathrm{VF}_{2}$ : $\mathrm{CTFE}=80: 20$, Solvay, Belgium) was desiccated at $50{ }^{\circ} \mathrm{C}$ for moisture removal. Dimethyl acetamide (DMAc, $>99 \%$ ) was obtained from Shanghai Jingwei Chemical Co., Ltd. (Shanghai, China). LiCl and polyethylene glycol (PEG) mixture at a mass ratio of $1: 1$ was used as the additives; both $\mathrm{LiCl}(\mathrm{AR},>95 \%)$ and PEG-400 (AR, >99. 5\%) were supplied by the Tianjin Guangfu Research Institute of Fine Chemical Engineering (Tianjin, China). Ethanol (GR grade, 99.9\%) and $\mathrm{NaCl}$ (GR grade, 99.5\%) were purchased from Beijing Chemical works (Beijing, China). Tap water was used as coagulant. All reagents were used as received except the PVDF-CTFE powder.

Membrane Preparation. PEG-400 (4 g) and $\mathrm{LiCl}(4 \mathrm{~g})$ were mixed with DMAc $(80 \mathrm{~g})$ in a sealed flask and stirred at $30{ }^{\circ} \mathrm{C}$ until all additives are completely dissoloved. Then $12 \mathrm{~g}$ of predesiccated PVDF-CTFE powder was added to the flask, and the mixture was continuously stirred for at least $24 \mathrm{~h}$ to obtain a homogeneous solution. Then the polymer solution was kept in a vacuum oven for at least $24 \mathrm{~h}$ for vacuum degassing at $30^{\circ} \mathrm{C}$.

Hydrophilic polyethylene terephthalate (PET) nonwoven fabric was used as the supporting material to prevent membrane shrinking and to enhance the mechanical strength, which was attached to a clean flat 
glass at the beginning. The degassed homogeneous casting solution was uniformly spread on the nonwoven fabric with a knife gap of 0.25 $\mathrm{mm}$ at $50{ }^{\circ} \mathrm{C}$. After being exposed in the oven for a predesigned time, the cast film was immersed into a $25^{\circ} \mathrm{C}$ water bath. Twenty-four hours later, the membrane was fetched out from the coagulation bath and rinsed with tap water to further remove the residual solvent and nonsolvent additives. Last, the wet membrane was air dried at room temperature. Nine membranes were prepared at different exposure durations to study the effect of exposure duration on PVDF-CTFE membranes (detailed membrane preparation conditions are listed in Table 1).

\section{Table 1. Preparation Conditions of PVDF-CTFE}

\section{Membranes}

\begin{tabular}{ccc}
$\begin{array}{c}\text { membrane } \\
\text { code }\end{array}$ & $\begin{array}{c}\text { exposure temperature and time } \\
\left({ }^{\circ} \mathrm{C}, \mathrm{s}\right)\end{array}$ & $\begin{array}{c}\text { coagulation temp. } \\
\left({ }^{\circ} \mathrm{C}\right)\end{array}$ \\
M1 & 50,0 & 25 \\
M2 & 50,5 & 25 \\
M3 & 50,10 & 25 \\
M4 & 50,30 & 25 \\
M5 & 50,60 & 25 \\
M6 & 50,180 & 25 \\
M7 & 50,300 & 25 \\
M8 & 50,600 & 25 \\
M9 & 50,1800 & 25 \\
\hline
\end{tabular}

Morphology. Field emission scanning electron microscopy (FESEM, HITACHI SU8020, Hitachi, Japan) was used for membrane morphology observation. The membranes were cryogenically fractured in liquid nitrogen for observation of the membrane cross-section. Before SEM observation, all samples were coated with gold nanoparticles under vacuum conditions by an ion sputtering device (HITACHI E-1010, Hitachi, Japan). An atomic force microscope (AFM, Shimadzu SPM-9600, Shimadzu, Japan) was employed to analyze the surface morphology and roughness of the flat-sheet membranes. All membranes were measured by tapping mode with the same probe at a scan size of $5.0 \mu \mathrm{m} \times 5.0 \mu \mathrm{m}$. The 3D surface morphology and depth distribution images were obtained as well as the mean surface roughness $R a$, the root-mean-square of the $\mathrm{Z}$ data $R q$, and the mean difference between the five highest peaks and lowest valleys $R z$.

Thermal and Crystalline Properties. The infrared spectrum of the membranes was evaluated using a Nicolet iS10 FTIR spectrometer (Thermo Scientific, USA). All spectra were recorded in a wavenumber range of $1600-650 \mathrm{~cm}^{-1}$ by cumulating 64 scans at a resolution of 4 $\mathrm{cm}^{-1}$. According to the spectrum, the content of $\beta$ phase $F_{\beta}$ was calculated by the following equation which has been widely applied $^{37-39}$

$$
F_{\beta}=\frac{A_{\beta}}{\left(K_{\beta} / K_{\alpha}\right) A_{\alpha}+A_{\beta}}
$$

where $A_{\alpha}$ and $A_{\beta}$ represent the absorbency at 766 ( $\alpha$ phase) and 840 $\mathrm{cm}^{-1}$ ( $\beta$ phase) and $K_{\alpha}$ and $K_{\beta}$ are the absorption coefficients at the respective wavenumber, the values of which are $6.1 \times 10^{4}$ and $7.7 \times$ $10^{4} \mathrm{~cm}^{2} / \mathrm{mol}$, respectively.

Differential scanning calorimetry (DSC) was used to determine the thermal properties (melting temperature $T_{\mathrm{m}}$ and crystallinity) of the membranes by a DSC 2 STAR $^{\mathrm{e}}$ system (Mettler Toledo, Switzerland). About $5 \mathrm{mg}$ of membrane coupons was torn off from the supporting layer and placed in a $40 \mu \mathrm{L}$ aluminum crucible. Then the crucible was placed in the instrument and heated from 80 to $250{ }^{\circ} \mathrm{C}$ at a rate of 10 ${ }^{\circ} \mathrm{C} / \mathrm{min}$. The heat flow was recorded, and then the crystallinity $\chi$ was calculated by the following equation ${ }^{40}$

$$
\chi=\frac{\Delta H_{\mathrm{m}}}{x\left(\Delta H_{100 \% \text { cryst }}\right)_{\alpha}+y\left(\Delta H_{100 \% \text { cryst }}\right)_{\beta}}
$$

where $x$ and $y$ are the fraction of $\alpha$ phase and $\beta$ phase, $\Delta H_{\mathrm{m}}$ is the recorded melting enthalpy of the membrane, and $\left(\Delta H_{100 \% \text { cryst. }}\right)_{\alpha}$ and $\left(\Delta H_{100 \% \text { cryst. }}\right)_{\beta}$ represent the melting enthalpy of the pure $\alpha$-PVDF and $\beta$-PVDF crystalline which are reported to be 93.04 and $103.4 \mathrm{~J} / \mathrm{g}$, respectively. ${ }^{41}$

Hydrophobicity. The hydrophobicity of the membrane was characterized by static water contact angles $\left(\mathrm{CA}_{\mathrm{w}}\right)$. The $\mathrm{CA}_{\mathrm{w}}$ of membranes were measured by an OCA 15EC Video-Based Contact Angle Meter (Data Physics, Germany); 5 positions were measured for each membrane.

Pore Structure. Membrane surface pore structure was analyzed according to the SEM micrographs; the pores in the membrane surface were marked in blue as shown in Figure S4 by the image-pro-plus 6.0 software (Media Cybernetics, USA). The minimum, maximum, and average pore sizes were recorded to represent the pore size in the membrane surface as well as the pore distribution. Surface porosity and the mean roundness of surface pores were also calculated to indicate the pore surface structure. The detailed method can be found in the Supporting Information.

The overall pore size and pore size distribution of the prepared membranes were investigated using a Capillary Flow Porometer Porolux 1000 (Porolux, Belgium) by the capillary flow method ${ }^{42}$ (detailed description can be found in the Supporting Information). The overall porosity $\varepsilon$ defined as the ratio of the volume of the overall pores and the total volume of the PVDF-CTFE layer was determined by the gravimetric method and calculated by the following equation

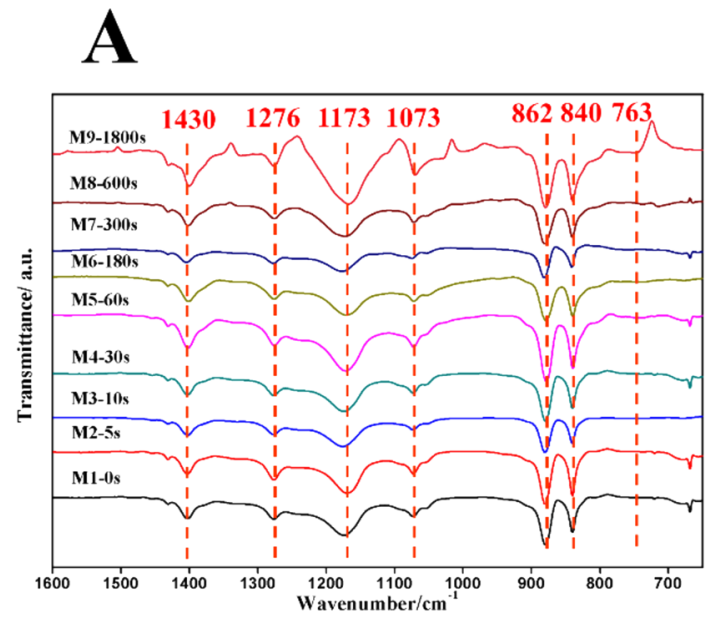

\section{B}

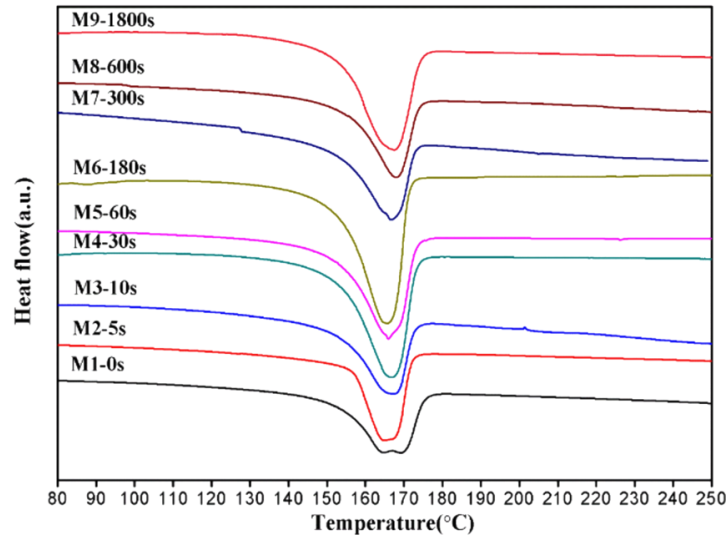

Figure 1. FTIR spectra (A) and DSC traces (B) of the PVDF-CTFE membranes. 
Table 2. Thermal, Crystallinity, Roughness, Hydrophobicity, and $\beta$-Phase Content of PVDF-CTFE Membranes

\begin{tabular}{|c|c|c|c|c|c|c|}
\hline membrane code & $\beta$-phase content (\%) & $T_{\mathrm{m}}\left({ }^{\circ} \mathrm{C}\right)$ & crystallinity (\%) & $\mathrm{Ra}(\mathrm{nm})$ & SEM roughness index & $\mathrm{CA}_{\text {water }}$ (deg) \\
\hline M1 & 87.50 & $164.67 \pm 0.35$ & 24.28 & 22.95 & 28.16 & $82.92 \pm 2.0$ \\
\hline M2 & 92.63 & $164.83 \pm 1.13$ & 24.50 & 29.39 & 29.13 & $82.30 \pm 1.6$ \\
\hline M3 & 90.36 & $167.33 \pm 0.57$ & 28.20 & 27.89 & 28.05 & $85.42 \pm 5.9$ \\
\hline M4 & 94.37 & $166.83 \pm 0.83$ & 30.19 & 32.74 & 29.39 & $85.50 \pm 0.7$ \\
\hline M5 & 92.69 & $166.00 \pm 1.25$ & 30.22 & 40.87 & 32.83 & $90.37 \pm 4.0$ \\
\hline M6 & 85.94 & $165.67 \pm 0.54$ & 30.52 & 40.30 & 33.89 & $97.74 \pm 1.8$ \\
\hline M7 & 80.13 & $166.67 \pm 0.76$ & 39.13 & 68.44 & 49.97 & $98.18 \pm 3.3$ \\
\hline M8 & 77.29 & $168.00 \pm 0.18$ & 38.59 & 146.60 & 43.11 & $102.38 \pm 1.2$ \\
\hline M9 & 73.06 & $167.50 \pm 1.04$ & 39.33 & 112.12 & 36.32 & $105.23 \pm 1.1$ \\
\hline
\end{tabular}
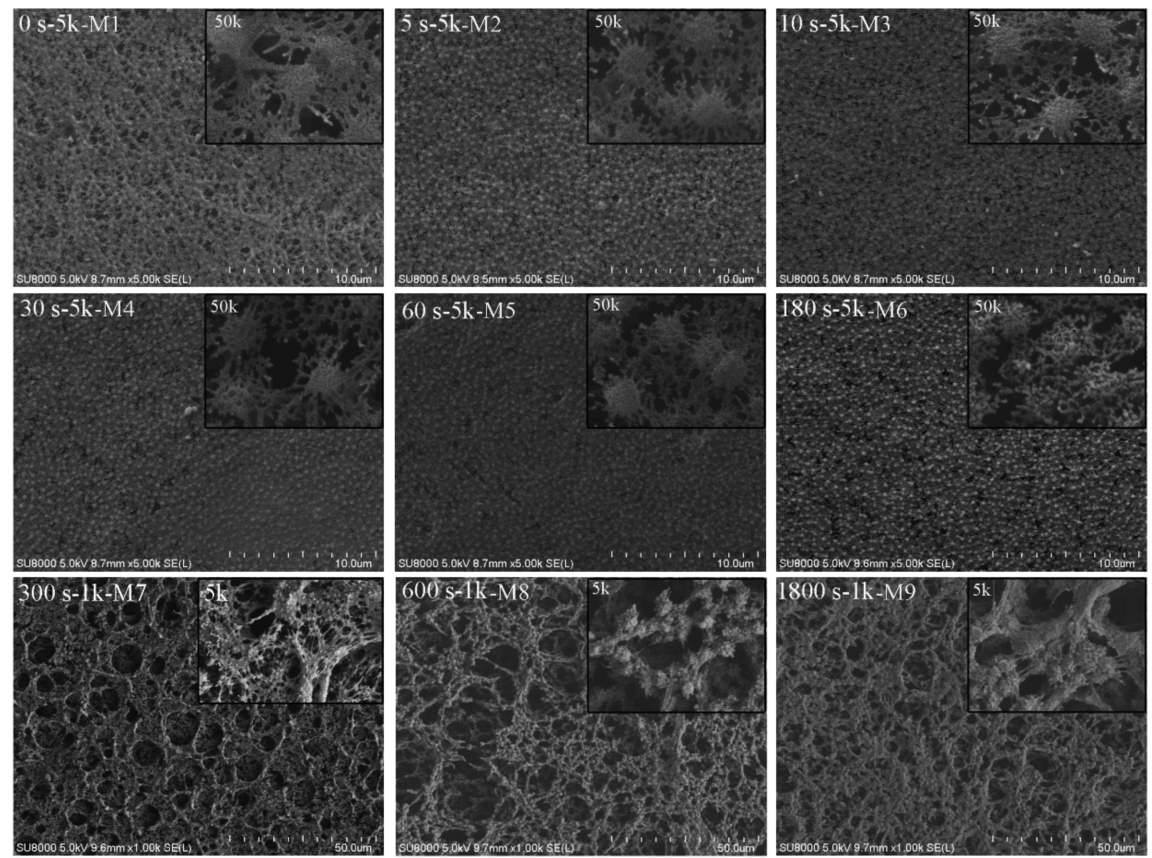

Figure 2. Membrane surface morphology by FE-SEM (M1-M6, 50000 magnified image inset in 5000 magnified image; M7-M9, 5000 magnified image inset in 1000 magnified image).

$$
\varepsilon=\frac{\left(M_{\mathrm{w}}-M_{\mathrm{d}}\right) / \rho_{\mathrm{w}}}{\left(M_{\mathrm{w}}-M_{\mathrm{d}}\right) / \rho_{\mathrm{w}}+M_{\mathrm{d}} / \rho_{\mathrm{p}}}
$$

where $M_{\mathrm{w}}$ is the weight of the wet membrane, $M_{\mathrm{d}}$ is the weight of the dry membrane, and $\rho_{\mathrm{w}}$ and $\rho_{\mathrm{p}}$ are the density of water and polymer powder, respectively. The detailed measurement method can be found in the Supporting Information.

Direct Contact Membrane Distillation (DCMD). A lab-scale DCMD setup as shown in Figure S1 was applied to study membrane permeability and sustainability (detailed conditions of the setup can be found in the Supporting Information). Feed solution ( $35 \mathrm{~g} / \mathrm{L}$ aqueous $\mathrm{NaCl}$ solution) flowed on the upper layer of PVDF-CTFE membrane, and distillated water was circulated on the surface of PET supporting layer; the flow rate of feed and permeate was kept constant at 65 and $50 \mathrm{~L} / \mathrm{h}$. Convection current was applied to prevent the accumulation of gas bubbles in the module which may influence the effective area of the membrane. The temperature on the inlet of the distillate and the feed solution was kept at 25 and $55{ }^{\circ} \mathrm{C}$, respectively.

\section{RESULTS AND DISCUSSION}

Membrane IR Spectrum and Thermal Properties. Figure 1A presents the Fourier transform infrared spectroscopy (FTIR) spectrum of the membranes; specific adsorption bands of $840,862,1073,1173,1276$, and $1430 \mathrm{~cm}^{-1}$ could be observed. That means both $\alpha$ - and $\beta$-phase existed in the

resultant membranes, as 763 and $862 \mathrm{~cm}^{-1}$ were the adsorption bands of $\alpha$-phase and 840 and $862 \mathrm{~cm}^{-1}$ indicate the presence of $\beta$-phase. ${ }^{37,40}$ Meanwhile, the polymorphs showed no variation as the exposure duration increased because no obvious variation can be found in the position of the characteristic peaks. However, the $\beta$-phase content varied as can be found in Table 2; it was about $90 \%$ for membranes M1M5, indicating that the $\beta$-phase was the dominant polymorph in all PVDF-CTFE membranes, while it decreased as the exposure duration was higher than $180 \mathrm{~s}$, which may result from the polymer crystallization process and the aggregate of the crystals in membrane which will be discussed in the SEM micrographs in Figure 2.

The thermal properties were also investigated; the DSC curves are presented in Figure 1B. All membranes exhibit almost similar melting temperatures $\left(T_{\mathrm{m}}\right)$ between 164 and 168 ${ }^{\circ} \mathrm{C}$, consistent with the $T_{\mathrm{m}}$ of $\alpha$-phase and $\beta$-phase. ${ }^{39,41}$ However, the $T_{\mathrm{m}}$ slightly increased with increasing exposure duration because of the increase of $\alpha$-phase content. Meanwhile, it was clear that the crystallinity increased when increasing the exposure duration, especially when the exposure time was higher than $300 \mathrm{~s}$ as shown in Table 2 . The increase of the $\alpha$-phase may be one reason, while the phase inversion during exposure stage was another reason. During the air 

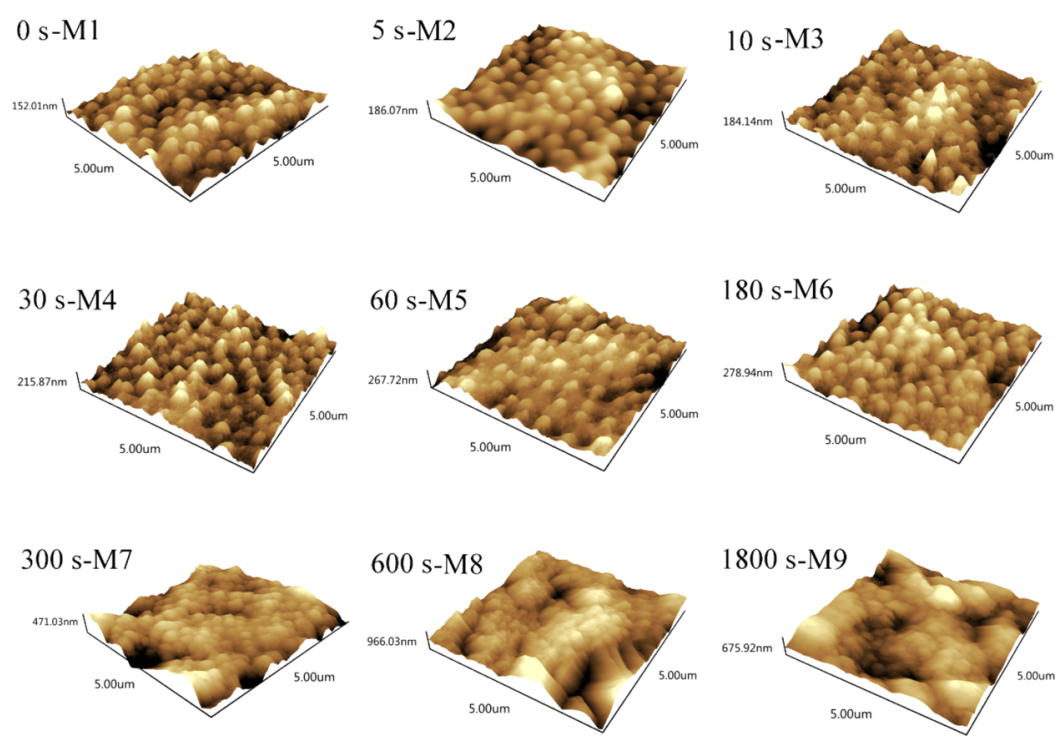

Figure 3. Three-dimension morphology of the membrane surface by AFM .

exposure stage in the oven at $50{ }^{\circ} \mathrm{C}$, the solvent evaporated after solution casting, so the polymer-rich phase would be formed and the gelation or crystallization process would be induced especially for the upper layer. When enhancing the air exposure stage, the solvent evaporation-induced phase inversion has more time to proceed and the gelation/ crystallization would process more thoroughly. As a result, the crystallinity of the membrane increased. Thus, it can be inferred that the phase inversion process by different exposure times would have a significant influence on the membrane morphology and properties.

Surface Morphology and Properties. Membrane skin layer was the function layer in the membrane process, so the morphology, especially the pore structure of the membrane surface, has a tremendous influence on the membrane separation performance. Meanwhile, the skin layer also influenced the subsequent phase inversion process of sublayers during membrane formation, which then influence the final membrane structure and performance. ${ }^{43}$

Figure 2 shows the SEM micrographs of the resultant membranes; M1-M6 are presented with $50000 \times$ magnified image inset in the 5000× magnified image; however, the 5000× magnified image was inset into the $1000 \times$ magnified image for M7-M9 because of the higher pore size. All membranes showed open porous structure with crystals in the surface, which presented a similar microstructure as the lotus leaf (for M1-M6) and the electrospun nanofiber membrane (for M7M9), because PVDF-CTFE has a higher crystallization tendency as confirmed in our previous work. ${ }^{44}$ The crystals and particles aggregate pore structure became more significant as the exposure duration increased especially as can be found in the inserted images in Figure 2. The membrane 3-D surface morphology and membrane surface depth distribution image recorded by AFM are presented in Figure 3 and Figure S2, respectively. The biomimetic micro/nanohierarchical structure was confirmed by Figure 3 as the polymer nodules can be found in the membrane surface. As a result, the roughness and crystals size increased along with the increasing exposure duration so as the water contact angle as shown in Table 2. Meanwhile, the roughness and hydrophobicity also presented a significant increasing trend as the exposure time was higher than $300 \mathrm{~s}$
(Table 2 and Table S1). The contact angle of all membranes was higher than $82^{\circ}$, so the PVDF-CTFE membranes were believed to be suitable in the MD process, while for $\mathrm{M} 7, \mathrm{M} 8$, and $\mathrm{M} 9$, the contact angles were $98.18^{\circ}, 102.38^{\circ}$, and $105.23^{\circ}$, respectively. The hydrophobicity was higher as compared to the original PVDF membranes without hydrophobic modification, which usually has a contact angle between $65^{\circ}$ and $80^{\circ}$.

The phase inversion process in the exposure stage was believed to be the main reason for membrane surface morphology variation. The solvent evaporated, and the gelation/crystallization process happened first on the airsolution interface as the solution had been casted. Thus, the polymer concentration became higher and the crystallization line was crossed; then the crystals were formed in the membrane surface, and papillose biomimetic structure can be found. For the membranes prepared by a shorter exposure stage, the $\mathrm{L}-\mathrm{L}$ demixing would immediately be induced as the cast film was immersed into a coagulation bath, even the $S-L$ demixing still proceeded in coagulation, so the net-like pores in membrane surface were formed as a result. When further increasing the exposure duration, more time was available for $\mathrm{S}-\mathrm{L}$ demixing and the crystals would aggregate together. It can be attributed to explain the open porous structure and nanofiber-like structure as shown in membranes M7-M9. This evidence clearly showed that the S-L demixing had a more significant influence when increasing the exposure duration, resulting from the higher concentration of polymer due to solvent evaporation and sufficient time for the gelation/ crystallization process. Thus, we can surely infer that the final morphology of the membrane surface was affected by the twostage phase inversion process as the exposure duration was lower than 180 s. However, when the exposure duration was higher than 300s, which can be viewed as an inflection point as also confirmed by the data of crystallinity, the nodules aggregation became more significant and the structure was similar to the membrane prepared by electrospinning. ${ }^{8,45}$ This indicates the phase inversion of the surface layer was almost complete after $300 \mathrm{~s}$ in air. Also, it is may be the reason why the inflection point can be observed.

The variation of surface roughness and hydrophobicity was also believed to be in consequence with polymer crystallization 
Table 3. Membrane Pore Structure in Terms of Pore Size, Porosity, and Roundness

\begin{tabular}{|c|c|c|c|c|c|c|}
\hline \multirow[b]{2}{*}{ membrane code } & \multicolumn{3}{|c|}{ surface pore structure } & \multicolumn{3}{|c|}{ overall pore structure } \\
\hline & pore $\operatorname{size}^{a}(\mu \mathrm{m})$ & porosity (\%) & roundness & pore $\operatorname{size}^{b}(\mu \mathrm{m})$ & pore $\operatorname{size}^{a}(\mu \mathrm{m})$ & porosity (\%) \\
\hline M1 & 0.1024 & 20.29 & 1.85 & $0.5097 \pm 0.073$ & $0.1130 \pm 0.040$ & $60.37 \pm 3.8$ \\
\hline M2 & 0.1217 & 24.37 & 2.10 & $0.2310 \pm 0.065$ & $0.1313 \pm 0.035$ & $61.00 \pm 0.4$ \\
\hline M3 & 0.1266 & 27.16 & 1.86 & $0.2255 \pm 0.038$ & $0.1436 \pm 0.021$ & $61.08 \pm 2.4$ \\
\hline M4 & 0.1140 & 24.04 & 1.79 & $0.3043 \pm 0.046$ & $0.1819 \pm 0.067$ & $64.26 \pm 3.7$ \\
\hline M5 & 0.1062 & 19.69 & 1.66 & $0.3685 \pm 0.068$ & $0.1788 \pm 0.043$ & $63.69 \pm 0.4$ \\
\hline M6 & 0.1194 & 26.20 & 2.08 & $0.5325 \pm 0.105$ & $0.1960 \pm 0.094$ & $71.93 \pm 2.3$ \\
\hline M7 & 0.3616 & 46.97 & 2.35 & $1.205 \pm 0.138$ & $0.2971 \pm 0.085$ & $54.68 \pm 3.4$ \\
\hline M8 & 0.4189 & 51.43 & 2.12 & $1.704 \pm 0.317$ & $0.6521 \pm 0.143$ & $50.98 \pm 1.1$ \\
\hline M9 & 0.3523 & 40.26 & 2.03 & $2.323 \pm 0.419$ & $0.9297 \pm 0.186$ & $50.84 \pm 1.0$ \\
\hline
\end{tabular}

during the phase inversion process. As the crystals formed more completely when the exposure duration was longer and aggregate together after the inflection point was passed, the surface roughness would increase as verified by both AFM and SEM image analysis (showed in Table 2 and Table S2) because of the presence of the crystals and crystalline nodules. The crystals and crystalline nodules in the membrane surface can also be used to explain the increase of contact angle, as the membrane hydrophobicity was highly consistent with the roughness in hydrophobic materials. ${ }^{44}$ On the basis of these considerations, the inflection point also had an effect on membrane roughness and hydrophobicity.

Membrane Surface Pore Structure. As can be found from the SEM micrographs displayed in Figure 2, the membrane surface pore structure was significantly influenced by the exposure stage. By further analysis of the $10000 \times$ magnified SEM micrographs (the original image can be found in Figure S4), detailed surface pore structure information was obtained and is listed in Table 3 and Table S2. A clear consistency can be found between the surface pore size and porosity; both increased in the beginning, then decreased, and finally significantly increased as the exposure duration was higher than $300 \mathrm{~s}$. A gel layer would first form due to the polymer gelation/crystallization happening in air because of solvent evaporation. ${ }^{46,47}$ Thus, the $S-L$ demixing would have a more significant role on the phase inversion process as exposure duration increased. When exposure time was shorter than $30 \mathrm{~s}$, the polymer-rich phase and polymer-lean phase separated more completely and benefit the pore formation process after being immersed in the coagulation bath as the exposure stage increased. As more exposure duration offered, the gel layer would in turn delay the phase inversion process in coagulation as the polymer concentration in the surface layer was higher due to evaporation of solvent. ${ }^{47}$ However, when the inflection point was surpassed, complete phase inversion was achieved for the surface layer and the crystals formed by solidification in air would aggregate and even formed electrospinning nofiber-like structure as shown in Figure 2. Thus, the pore size and porosity in the membrane surface would increase again due to the high exchange rate of solvent and nonsolvent after immersion. It also worth noting that the roundness of the pores presents a highly relevant trend with pore size, which is also strongly related to the polymer solidification process.

The surface pore distribution was also obtained by SEM image analysis as shown in Figure 4. The pore size increased, decreased, and reincreased with increasing exposure time as Table 3 shows. It was also interesting to find that the surface

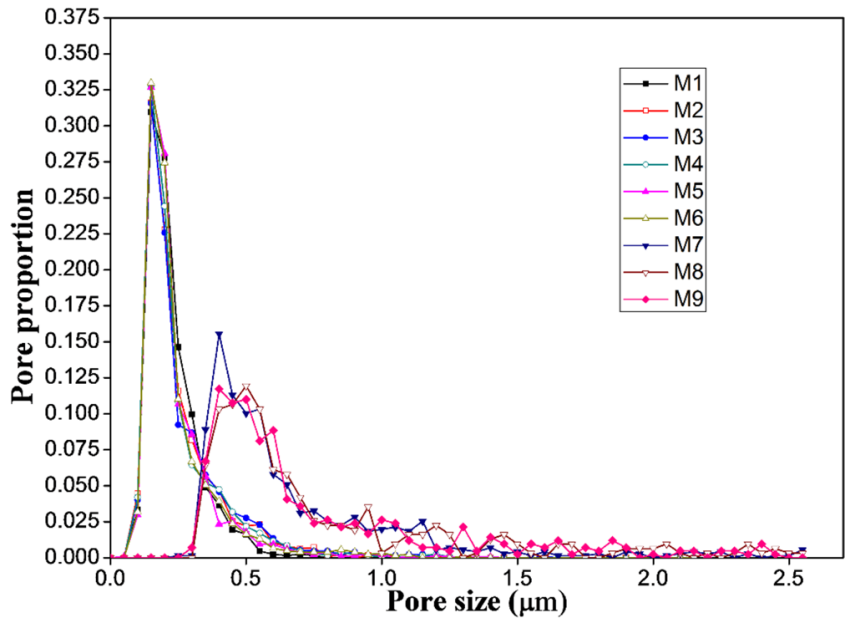

Figure 4. Pore size distribution of membrane surface pores.

pore distribution remained narrow and centralized for membranes M1-M6 as exposure duration was lower than $180 \mathrm{~s}$, which became much broader and decentralized when the inflection point was surpassed. The crystal aggregation was believed to be the main reason for the variation in the pore distribution, which was also consistent with the membrane surface morphology and pore size. In other words, the variation in the pore structure was also significantly influenced by the phase inversion process in the air exposure stage and immersing stage.

Membrane Cross-Section Structure. The SEM images of the membranes cross-section are presented in Figure S5 to illustrate the effect of the exposure stage on the morphology and pore structure of the membrane cross-section. All membranes showed asymmetric structure constituted by a top layer, macrovoids, and sponge-like sublayer typically formed by $\mathrm{L}-\mathrm{L}$ demixing when the exposure duration was lower than $180 \mathrm{~s}$. However, the pore interconnectivity increased in both the macrovoids and the sublayer (sponge-like layer) as the exposure time increased. Distinguishingly, when the exposure time was higher than 300 s, i.e., the inflection point, the membranes presented symmetric structure with polymer crystals. Two stages of macrovoids suppression can also be found, which was also reported for PSf hollow fiber membranes, ${ }^{46}$ and the phase inversion process that happened in the exposure stage was believed to be the reason in that work. To further study the phase inversion process during the air exposure stage and the coagulation stage, especially their interactive effects on the resultant membranes, the upper layer 

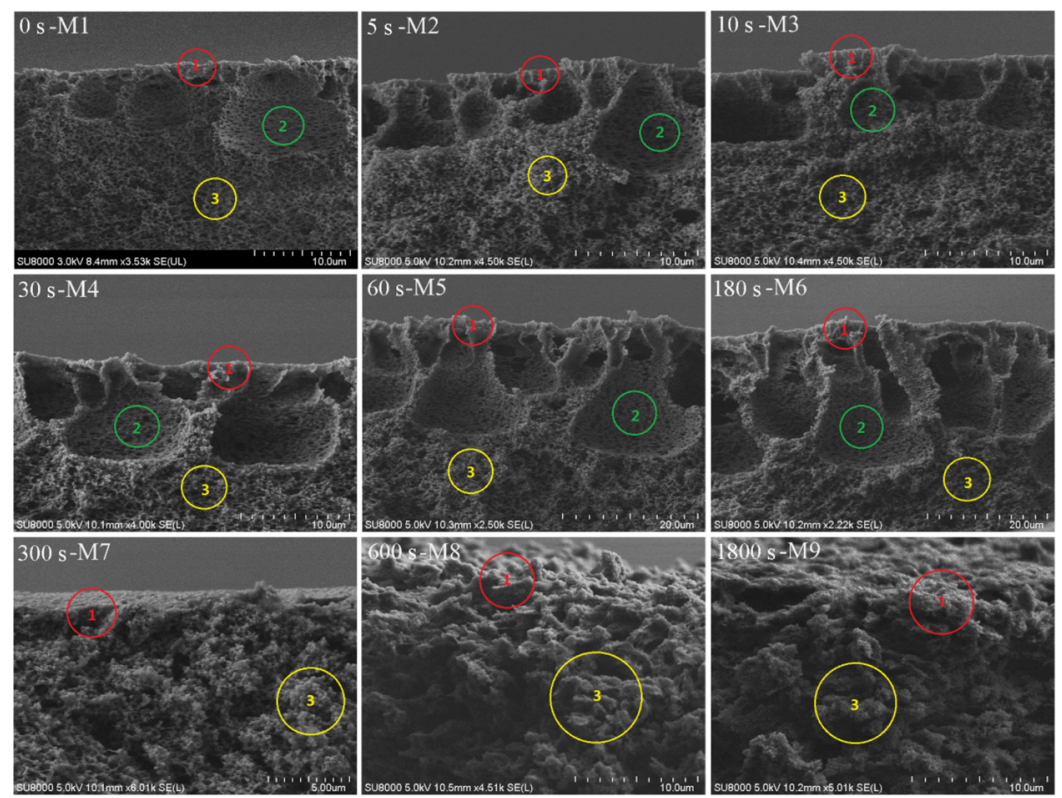

Figure 5. Morphology of the upper layers of the membrane cross-section.

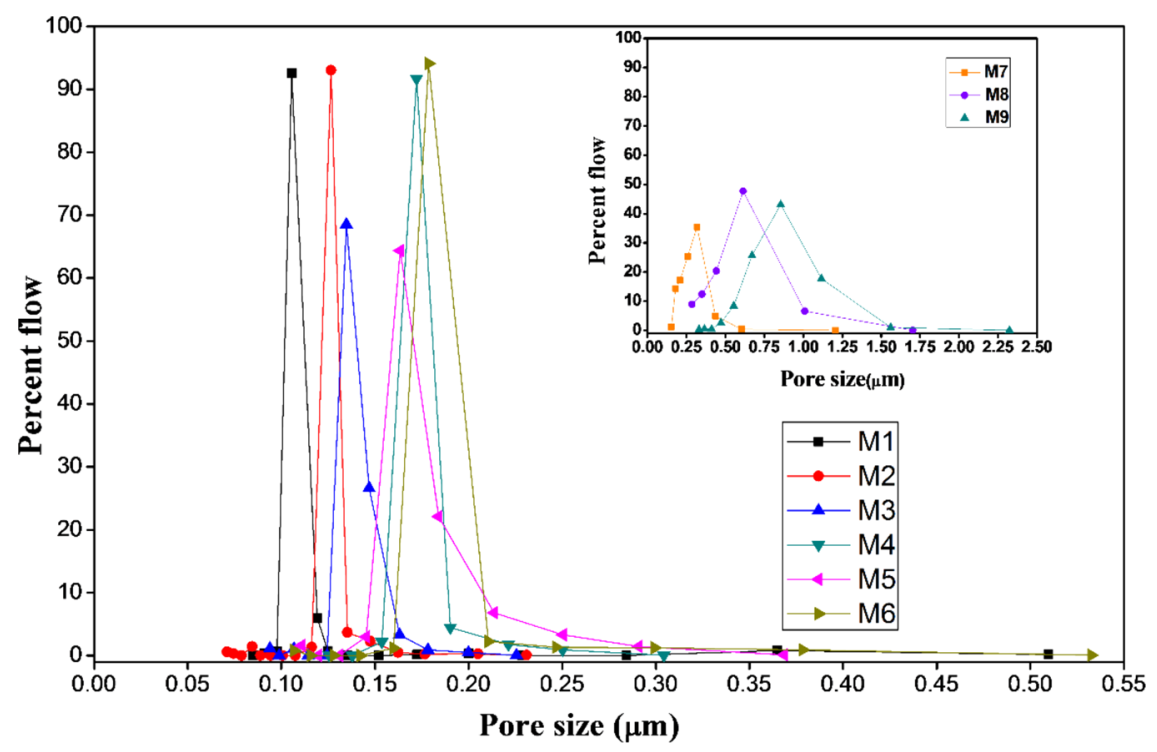

Figure 6. Pore size distribution of membrane overall pores.

near the top layer was carefully observed by FE-SEM. It can be found in Figure 5 that the membrane top layer (1) became thinner and more porous as the exposure duration extended; it even disappeared when the time was higher than $300 \mathrm{~s}$. The macrovoids layer (2) also presented the same trend as the top layer with interconnected and particulate pore structure. As for the sublayer (4), Figure 5 clearly shows that the interconnectivity increased with increasing exposure duration.

The two-stage phase inversion processes during the air exposure and coagulation stage were responsible for the final cross-section morphology and the pore structure. As the twostage phase inversion strategy was applied, the crystallization/ gelation in the air exposure stage and rapid $\mathrm{L}-\mathrm{L}$ demixing in the coagulation bath worked together to influence the final membrane. Meanwhile, the $\mathrm{S}-\mathrm{L}$ demixing still goes on when cast film was immersed in the coagulation bath. As we know, the membrane formed by $\mathrm{S}-\mathrm{L}$ demixing and $\mathrm{L}-\mathrm{L}$ demixing has a different morphology and structure. The $\mathrm{L}-\mathrm{L}$ demixing dominates the phase inversion process when the exposure stage was short (lower than $180 \mathrm{~s}$ ), because the $\mathrm{L}-\mathrm{L}$ demixing happened immediately after immersion. However, the $\mathrm{S}-\mathrm{L}$ demixing showed more influence when increasing the exposure duration. One reason is that the time for solvent evaporation in air was longer which induced more complete crystallization. The other reason is that the exchange of solvent and nonsolvent was impeded because of the gel layer in the membrane surface formed in air, so more time was available for $\mathrm{S}-\mathrm{L}$ demixing in the coagulation bath, which then resulted in the interconnected particulate structure, and the macrovoids were also suppressed because of the existence of the top layer. That also explained the higher pore interconnectivity, bigger nodules, and more symmetric structure of the cross-section. When the exposure time was higher than $300 \mathrm{~s}$, the formation of the membrane surface layer was almost complete, the $\mathrm{S}-\mathrm{L}$ demixing dominates the phase inversion process, and the symmetric membrane was obtained. However, the membrane 


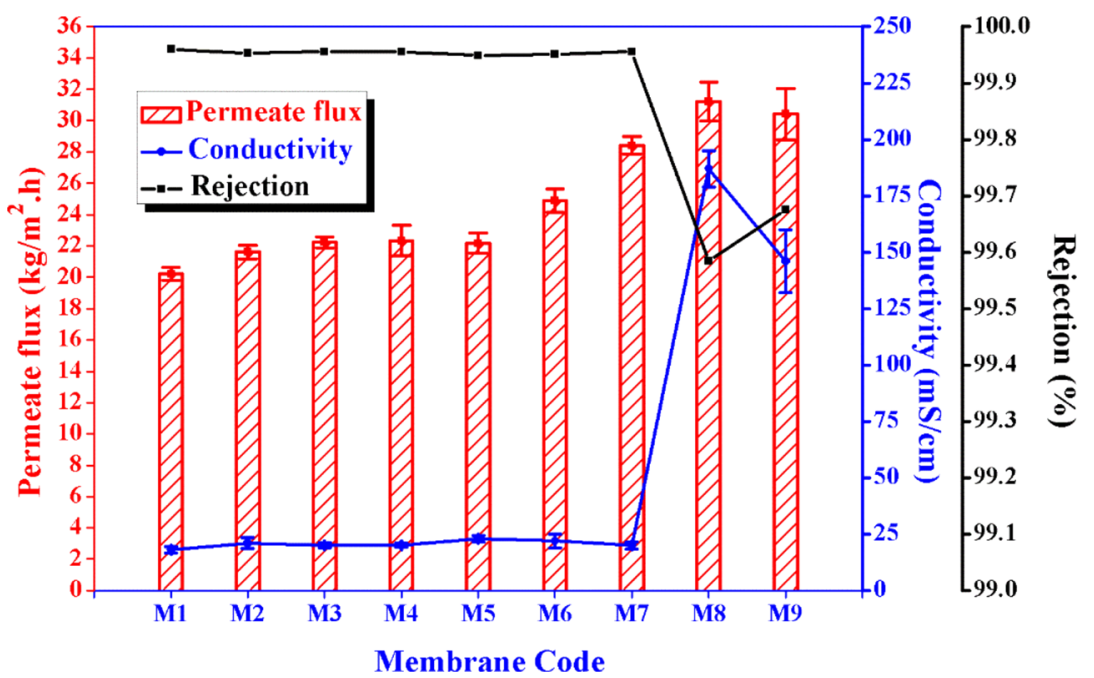

Figure 7. Membrane permeate flux and conductivity in DCMD desalination process (feed temperature, $55^{\circ} \mathrm{C}$; permeate temperature, $25{ }^{\circ} \mathrm{C}$ ).

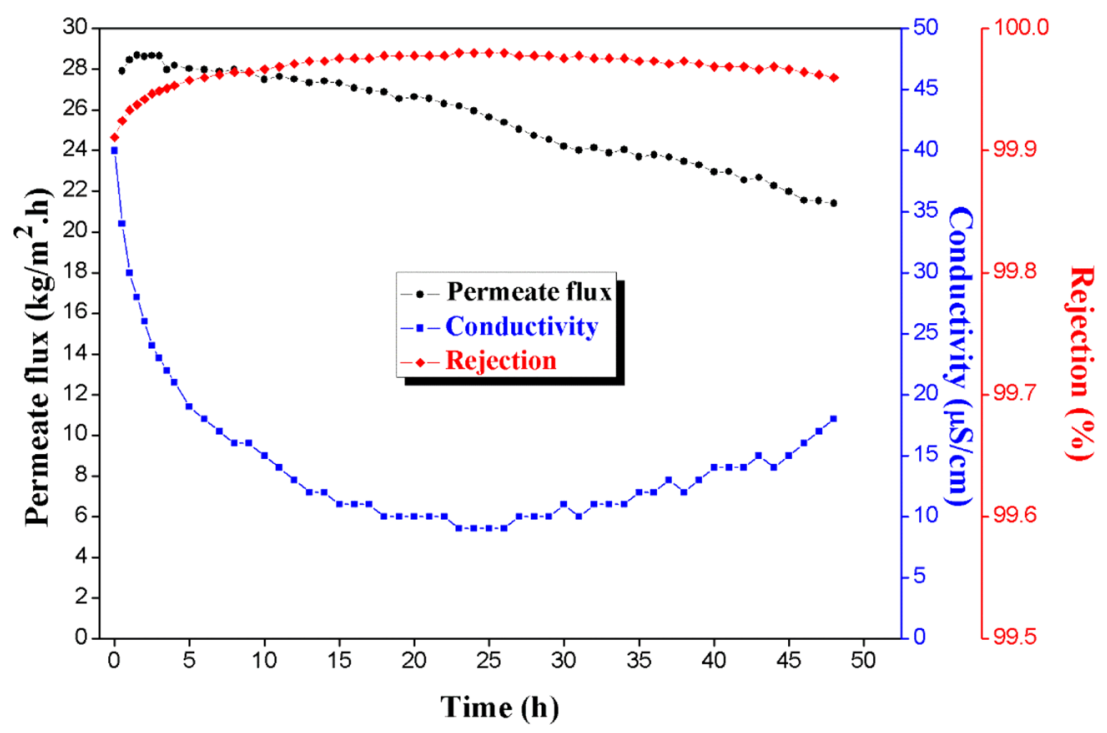

Figure 8. Permeate flux and conductivity of PVDF-CTFE membrane during a $48 \mathrm{~h}$ continuous $\mathrm{MD}$ operation (feed temperature, $55{ }^{\circ} \mathrm{C}$; permeate temperature, $\left.25^{\circ} \mathrm{C}\right)$.

interconnectivity decreased as the exposure time was higher than $300 \mathrm{~s}$ because of the aggregation of crystals due to the S$\mathrm{L}$ demixing process before immersion. The particles in the surface even aggregate to form a bigger crystalline structure or nanofiber-like structure. In other words, the membrane prepared by exposure times higher than $300 \mathrm{~s}$ can be considered to be prepared by a solvent evaporation-induced phase inversion as the solidification process was almost finished in the exposure stage, especially for the upper layers.

Membranes Overall Pore Structure. The surface pore structure significantly influences the rejection performance (or separation factor) in the membrane process, while the overall pore structure would highly relate to membrane permeability. Pore size including bubble point, minimum, mean pore size, and the overall porosity were measured here to study the effect of exposure duration on the membrane overall pore structure, and the results are shown in Table 3 and Table S2. It can be found that the membrane pore size and overall porosity increased along with the exposure duration, and an inflection point at $300 \mathrm{~s}$ can also be observed. The competition of S-L demixing and $\mathrm{L}-\mathrm{L}$ demixing during the two-stage phase inversion process was believed to be the main reason. The pore size distribution of the membranes is presented in Figure 6. A narrow and centralized pore distribution was obtained when exposure time was less than $180 \mathrm{~s}$, and it became remarkably broader and decentralized when exposure duration was longer than $300 \mathrm{~s}$ as the crystals aggregated together, which was in accordance with the pore size data shown in Table 3 .

Membrane Distillation Performance. As it was surely believed that the phase inversion in the exposure stage had a significant influence on PVDF-CTFE membrane morphology, pore structure, crystalline property, and hydrophobicity with the presence of inflection point, the exposure stage must have an impact on membrane performance. The results of the MD test including permeate flux and conductivity are presented in Figure 7. A significantly increasing trend can be found as the exposure duration was higher than the inflection point, while before it, the flux showed no apparent variation. A flux of 31.23 $\mathrm{kg} / \mathrm{m}^{2} \cdot \mathrm{h}$ was achieved for membrane M8; however, the conductivity increased quickly and achieved $187 \mu \mathrm{S} / \mathrm{cm}$ after $2 \mathrm{~h}$ operation. Thus, although the flux of M8 and M9 was high, they are not suitable for the $\mathrm{MD}$ process due to the pore- 


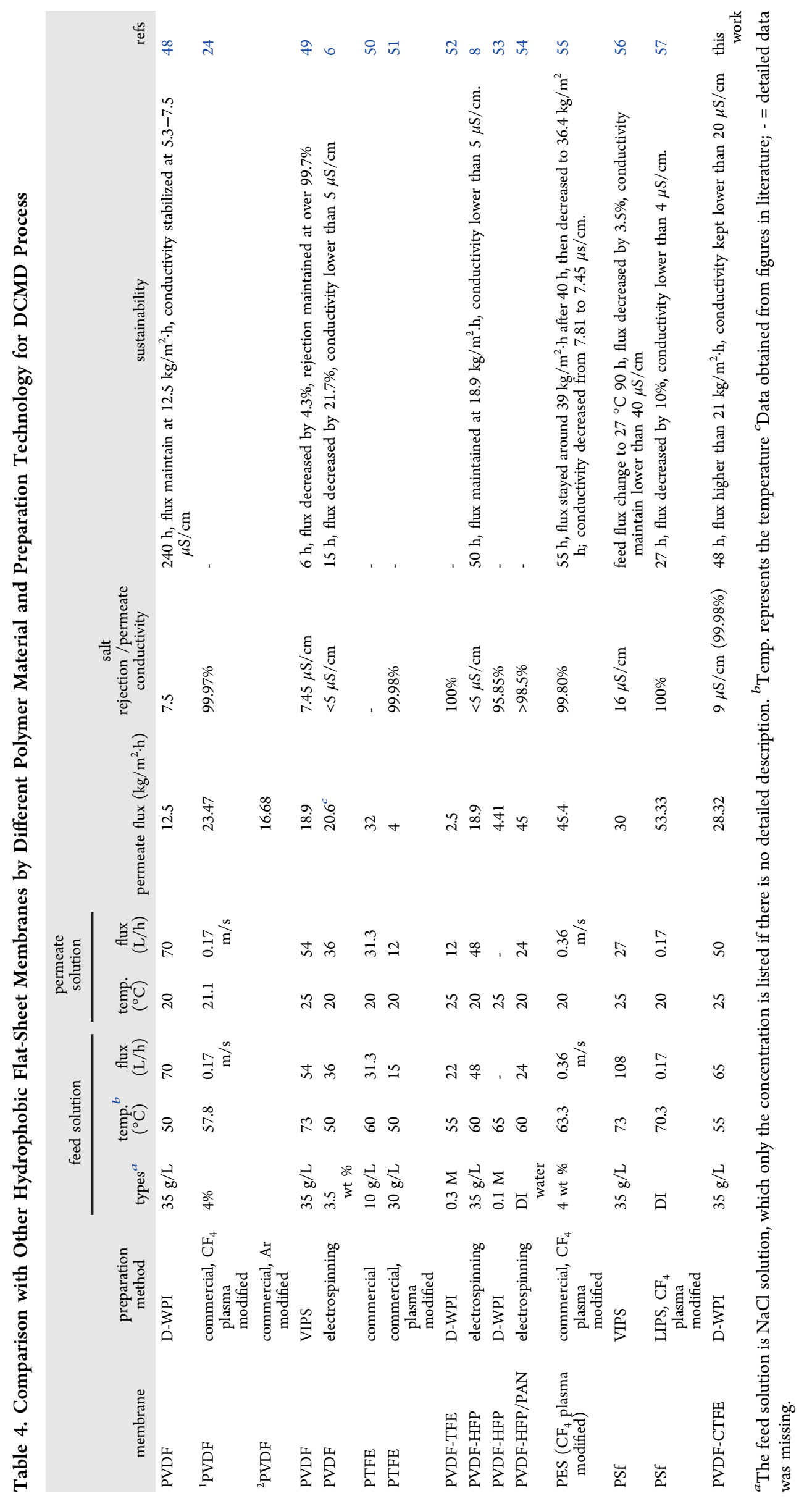


wetting issue. The hydrophobic membrane permeability was strongly related to the pore size and pore interconnectivity, while the rejection was related to pore size and hydrophobicity. To prevent pore-wetting issue, a membrane with a higher hydrophobicity can sustain a larger pore and vice versa. That means a boundary of pore size theoretically existed for a membrane material with a fixed hydrophobicity. For M8 and M9, the pore size may be so large that exceeding the biggest pore size the membrane can sustain with certain hydrophobicity, though the hydrophobicity of both were relatively high $\left(\mathrm{CA}_{\text {water }}\right.$ of $102^{\circ}$ and $105^{\circ}$ for M8 and M9 as shown in Table 2).

Membrane M7 under $300 \mathrm{~s}$ exposure duration seems to be the optimal membrane in this work, with a permeate flux of $28.43 \mathrm{~kg} / \mathrm{m}^{2} \cdot \mathrm{h}$ and conductivity of $20 \mu \mathrm{S} / \mathrm{cm}$ (salt rejection = $99.96 \%)$. In this regard, this membrane was applied to a continuous $48 \mathrm{~h} \mathrm{MD}$ test to study the sustainability, and the result is presented in Figure 8. It can be found that the conductivity decreased quickly especially in the first $2 \mathrm{~h}$, indicating permeate with high flux and low conductivity. The permeate conductivity was $9 \mu \mathrm{S} / \mathrm{cm}$ after $22 \mathrm{~h}$ operation, which can be considered as the permeate conductivity with an assumption that original distillated water was totally discharged. The conductivity increased gradually $26 \mathrm{~h}$ later, which may be the result of pore wetting. However, the conductivity was kept lower than $20 \mu \mathrm{S} / \mathrm{cm}$ during the $48 \mathrm{~h}$ continuous operation, and the rejection was still higher than $99.95 \%$. Meanwhile, the permeate flux was kept constant in the first $20 \mathrm{~h}$, and then it decreased by less than $25 \%$, which was still kept higher than 21 $\mathrm{kg} / \mathrm{m}^{2} \cdot \mathrm{h}$ during the whole operation. The relatively high hydrophobicity, high roughness, narrow pore distribution, but interconnected pore structure was believed to be the reason for the excellent performance of the membrane M7 as discussed.

Comparison with Hydrophobic Membranes Applied in the MD Process in the Literature. A comparison with other hydrophobic polymer membranes for DCMD application reported in recent years was carried out and is listed in Table 4. ${ }^{6,8,25,48-57}$ It can be found that the PVDF-CTFE membrane prepared in this work presented a competitive advantage in permeate flux with other reported hydrophobic membrane, although some of them have been carefully hydrophobically modified. As to the membrane sustainability, the permeate flux and the conductivity of the PVDF-CTFE membrane in this work were kept stable during the $48 \mathrm{~h}$ operation, which also showed certain advantages as compared to some previous research. It was safe to say that PVDF-CTFE copolymer has noteworthy potential for hydrophobic membrane preparation and application, especially when more efforts have been paid to prepare and modify the membrane.

\section{CONCLUSIONS}

In the present work, PVDF-CTFE hydrophobic flat-sheet membranes with a biomimetic surface and interconnected pore structure were manufactured by a facile two-stage phase inversion method (i.e., EIPS and DIPS) for the first time. The phase inversion process during membrane formation was controlled by tuning the duration of the exposure stage to acquire an ideal structure. It was found that the exposure stage benefited crystallization due to the solvent evaporation-induced phase inversion in air, which indicates that the $\mathrm{S}-\mathrm{L}$ demixing process can be controlled by tuning the exposure duration. The biomimetic surface and interconnected pore structure can be expected due to the gelation/crystallization, which has been evidenced by membrane crystallinity. Meanwhile, an inflection point (i.e., $300 \mathrm{~s}$ ) was observed in this work, above which the drastic variation would appear. The MD flux showed an agreement with the pore size, while the rejection possessed a reverse trend. M7 with $300 \mathrm{~s}$ air exposure is the optimal membrane with a permeate flux of $28.43 \mathrm{~kg} / \mathrm{m}^{2} \cdot \mathrm{h}$ and a conductivity of $9 \mu \mathrm{S} / \mathrm{cm}$, which also had a relatively stable performance during a $48 \mathrm{~h}$ continuous MD operation.

The results presented in this work clearly demonstrated that a two-stage phase inversion process happens in the air-casting and immersion processes, which has a significant influence on membrane morphology, structure, properties, and performance. It also surely believed that membrane with biomimetic hydrophobic structure and excellent interconnectivity can be expected by carefully controlling the phase inversion process during membrane formation.

\section{ASSOCIATED CONTENT}

\section{S Supporting Information}

The Supporting Information is available free of charge on the ACS Publications website at DOI: 10.1021/acsami.6b11249.

Surface pore structure study by image-pro-plus 6.0 and image J, overall porosity measurement, overall pore size and pore distribution by capillary flow method, DCMD process; schematic diagram of the DCMD setup and design diagram of the flat-sheet membrane module, membrane surface depth distribution image by AFM, membrane surface morphology plotted by grayscale values of SEM images, SEM micrographs of membrane surface for pore structure analysis, SEM micrographs of membrane cross-section; Surface roughness of PVDFCTFE membranes, pore size of PVDF-CTFE membranes (PDF)

\section{AUTHOR INFORMATION}

\section{Corresponding Authors}

*E-mail: junwang@rcees.ac.cn. Tel: +86 10 62849198. Fax: +86 1062849198.

*E-mail: yswei@rcees.ac.cn. Tel: +86 10 62849198. Fax: +86 1062849198.

\section{ORCID}

Libing Zheng: 0000-0001-8427-7514

Notes

The authors declare no competing financial interest.

\section{ACKNOWLEDGMENTS}

This work was supported by the National Natural Science Foundation of China (Grant Nos. 51378491 and 51578533) and the National Key Research and Development Program of China (Grant No. 2016YFC0400501).

\section{REFERENCES}

(1) Findley, M. Vaporization through Porous Membranes. Ind. Eng. Chem. Process Des. Dev. 1967, 6 (2), 226-230.

(2) Pangarkar, B. L.; Sane, M. G.; Parjane, S. B.; Guddad, M. Status of Membrane Distillation for Water and Wastewater Treatment-A review. Desalin. Water Treat. 2014, 52 (28-30), 5199-5218.

(3) Wang, P.; Chung, T. S. Recent Advances in Membrane Distillation Processes: Membrane Development, Configuration Design and Application Exploring. J. Membr. Sci. 2015, 474, 39-56.

(4) Alkhudhiri, A.; Darwish, N.; Hilal, N. Membrane Distillation: A Comprehensive Review. Desalination 2012, 287, 2-18. 
(5) Camacho, L. M.; Dumée, L.; Zhang, J.; Li, J. D.; Duke, M.; Gomez, J.; Gray, S. Advances in Membrane Distillation for Water Desalination and Purification Applications. Water 2013, 5 (1), 94196.

(6) Liao, Y.; Wang, R.; Tian, M.; Qiu, C.; Fane, A. G. Fabrication of Polyvinylidene F luoride (PVDF) Nanofiber Membranes by Electrospinning for Direct Contact Membrane Distillation. J. Membr. Sci. 2013, 425-426, 30-39.

(7) Lin, S.; Nejati, S.; Boo, C.; Hu, Y.; Osuji, C. O.; Elimelech, M. Omniphobic Membrane for Robust Membrane Distillation. Environ. Sci. Technol. Lett. 2014, 1 (11), 443-447.

(8) Liao, Y.; Wang, R.; Fane, A. G. Fabrication of Bioinspired Composite Nanofiber Membranes with Robust Superhydrophobicity for Direct Contact Membrane Distillation. Environ. Sci. Technol. 2014, 48 (11), 6335-6341.

(9) Li, X.; Wang, C.; Yang, Y.; Wang, X.; Zhu, M.; Hsiao, B. S. Dualbiomimetic Superhydrophobic Electrospun Polystyrene Nanofibrous Membranes for Membrane Distillation. ACS Appl. Mater. Interfaces 2014, 6 (4), 2423-2430.

(10) Eykens, L.; De Sitter, K.; Dotremont, C.; Pinoy, L.; Van der Bruggen, B. Characterization and Performance Evaluation of Commercially Available Hydrophobic Membranes for Direct Contact Membrane Distillation. Desalination 2016, 392, 63-73.

(11) Szczepanski, C. R.; Darmanin, T.; Guittard, F. Spontaneous, Phase-Separation Induced Surface Roughness: A New Method to Design Parahydrophobic Polymer Coatings with Rose Petal-like Morphology. ACS Appl. Mater. Interfaces 2016, 8 (5), 3063-3071.

(12) Wang, Z.; Elimelech, M.; Lin, S. Environmental Applications of Interfacial Materials with Special Wettability. Environ. Sci. Technol. 2016, 50 (5), 2132-2150.

(13) Wang, N.; Xiong, D. Comparison of Micro-/nano-hierarchical and Nano-scale Roughness of Silica Membranes in Terms of Wetting Behavior and Transparency. Colloids Surf., A 2014, 446, 8-14.

(14) Li, X.; Zhou, C.; Du, R.; Li, N.; Han, X.; Zhang, Y.; An, S.; Xiao, C. Evolution of Polyvinylidene Fluoride (PVDF) Hierarchical Morphology during Slow Gelation Process and Its Superhydrophobicity. ACS Appl. Mater. Interfaces 2013, 5 (12), 5430-5435.

(15) Razmjou, A.; Arifin, E.; Dong, G.; Mansouri, J.; Chen, V. Superhydrophobic Modification of $\mathrm{TiO}_{2}$ Nanocomposite PVDF Membranes for Applications in Membrane Distillation. J. Membr. Sci. 2012, 415-416, 850-863.

(16) Zhang, J.; Song, Z.; Li, B.; Wang, Q.; Wang, S. Fabrication and Characterization of Superhydrophobic Poly (vinylidene fluoride) Membrane for Direct Contact Membrane Distillation. Desalination 2013, 324, 1-9.

(17) Efome, J. E.; Baghbanzadeh, M.; Rana, D.; Matsuura, T.; Lan, C. Q. Effects of Superhydrophobic $\mathrm{SiO}_{2}$ Nanoparticles on the Performance of PVDF Flat Sheet Membranes for Vacuum Membrane Distillation. Desalination 2015, 373, 47-57.

(18) Li, X.; Yu, X.; Cheng, C.; Deng, L.; Wang, M.; Wang, X. Electrospun Superhydrophobic Organic/inorganic Composite Nanofibrous Membranes for Membrane Distillation. ACS Appl. Mater. Interfaces 2015, 7 (39), 21919-21930.

(19) Hu, L.; Zhang, S.; Zhang, Y.; Li, B. A Flexible Nanofiber-based Membrane with Superhydrophobic Pinning Properties. J. Colloid Interface Sci. 2016, 472, 167-172.

(20) Liao, Y.; Wang, R.; Fane, A. G. Engineering Superhydrophobic Surface on Poly (vinylidene fluoride) Nanofiber Membranes for Direct Contact Membrane Distillation. J. Membr. Sci. 2013, 440, 77-87.

(21) Guo, F.; Servi, A.; Liu, A.; Gleason, K. K.; Rutledge, G. C. Desalination by Membrane Distillation using Electrospun Polyamide Fiber Membranes with Surface Fluorination by Chemical Vapor Deposition. ACS Appl. Mater. Interfaces 2015, 7 (15), 8225-8232.

(22) Dong, Z. Q.; Wang, B. J.; Ma, X. H.; Wei, Y. M.; Xu, Z. L. FAS Grafted Electrospun Poly (vinyl alcohol) Nanofiber Membranes with Robust Superhydrophobicity for Membrane Distillation. ACS Appl. Mater. Interfaces 2015, 7 (40), 22652-22659.

(23) Jalal, T. A.; Bettahalli, N. S.; Le, N. L.; Nunes, S. P. Hydrophobic Hyflon AD/Poly (vinylidene fluoride) Membranes for
Butanol Dehydration via Pervaporation. Ind. Eng. Chem. Res. 2015, 54 (44), 11180-11187.

(24) Zhou, H.; Shi, R.; Jin, W. Novel Organic-inorganic Pervaporation Membrane with a SuperhydrophobicSurface for the Separation of Ethanol from an Aqueous Solution. Sep. Purif. Technol. 2014, 127, 61-69.

(25) Yang, C.; Li, X. M.; Gilron, J.; Kong, D.-f.; Yin, Y.; Oren, Y.; Linder, C.; He, T. $\mathrm{CF}_{4}$ Plasma-modified Superhydrophobic PVDF Membranes for Direct Contact Membrane Distillation. J. Membr. Sci. 2014, 456, 155-161.

(26) Dong, Z. Q.; Ma, X. H.; Xu, Z. L.; You, W. T.; Li, F. B. Superhydrophobic PVDF-PTFE Electrospun Nanofibrous Membranes for Desalination by Vacuum Membrane Distillation. Desalination 2014, 347, 175-183.

(27) Gurav, A. B.; Guo, Q.; Tao, Y.; Mei, T.; Wang, Y.; Wang, D. Durable, Robust and Free-standing Superhydrophobic Poly(vinyl alcohol-co-ethylene) Nanofiber Membrane. Mater. Lett. 2016, 182, 106-109.

(28) Zheng, L.; Wu, Z.; Wei, Y.; Zhang, Y.; Yuan, Y.; Wang, J. Preparation of PVDF-CTFE Hydrophobic Membranes for MD Application: Effect of LiCl-based Mixed Additives. J. Membr. Sci. 2016, 506, 71-85.

(29) Liu, F.; Tao, M. M.; Xue, L. X. PVDF Membranes with Interconnected Pores Prepared via a Nat-ips Process. Desalination 2012, 298, 99-105.

(30) Subramanian, S.; Seeram, R. New Directions in Nanofiltration Applications-Are nanofibers the Right Materials as Membranes in Desalination? Desalination 2013, 308, 198-208.

(31) Mulder, M. Basic Principles of Membrane Technology; Springer Science \& Business Media, 1996.

(32) Ren, J.; Wang, R., Preparation of Polymeric Membranes. Membrane and desalination technologies; Springer, 2011; pp 47-100.

(33) Menut, P.; Su, Y.; Chinpa, W.; Pochat-Bohatier, C.; Deratani, A.; Wang, D.; Huguet, P.; Kuo, C.; Lai, J.; Dupuy, C.; Top, A Surface Liquid Layer During Membrane Formation using Vapor-induced Phase Separation (VIPS)-Evidence and Mechanism of Formation. J. Membr. Sci. 2008, 310 (1), 278-288.

(34) Fan, H.; Peng, Y.; Li, Z.; Chen, P.; Jiang, Q.; Wang, S. Preparation and Characterization of Hydrophobic PVDF Membranes by Vapor-induced Phase Separation and Application in Vacuum Membrane Distillation. J. Polym. Res. 2013, 20 (6), 1-15.

(35) Ahmad, A.; Ramli, W. Hydrophobic PVDF Membrane via Twostage Soft Coagulation Bath System for Membrane Gas Absorption of $\mathrm{CO}_{2}$. Sep. Purif. Technol. 2013, 103, 230-240.

(36) Thomas, R.; Guillen-Burrieza, E.; Arafat, H. A. Pore Structure Control of PVDF Membranes using a 2-stage Coagulation Bath Phase Inversion Process for Application in Membrane Distillation (MD). J. Membr. Sci. 2014, 452, 470-480.

(37) Sousa, R. E.; Ferreira, J. C. C.; Costa, C.; Machado, A. V.; Silva, M. M.; Lanceros-Mendez, S. Tailoring Poly (vinylidene fluoride-cochlorotrifluoroethylene) Microstructure and Physicochemical Properties by Exploring its Binary Phase Diagram with Dimethylformamide. J. Polym. Sci., Part B: Polym. Phys. 2015, 53 (11), 761-773.

(38) Gregorio, R., Jr.; Cestari, M. Effect of Crystallization Temperature on the Crystalline Phase Content and Morphology of Poly (vinylidene fluoride). J. Polym. Sci., Part B: Polym. Phys. 1994, 32 (5), 859-870.

(39) Cardoso, V. F.; Botelho, G.; Lanceros-Méndez, S. Nonsolvent Induced Phase Separation Preparation of Poly (vinylidene fluoride-cochlorotrifluoroethylene) Membranes with Tailored Morphology, Piezoelectric Phase Content and Mechanical Properties. Mater. Des. 2015, 88, 390-397.

(40) Martins, P.; Lopes, A.; Lanceros-Mendez, S. Electroactive Phases of Poly (vinylidene fluoride): Determination, Processing and Applications. Prog. Polym. Sci. 2014, 39 (4), 683-706.

(41) Tao, M. M.; Liu, F.; Ma, B. R.; Xue, L. X. Effect of Solvent Power on PVDF Membrane Polymorphism during Phase Inversion. Desalination 2013, 316, 137-145. 
(42) Agarwal, C.; Pandey, A. K.; Das, S.; Sharma, M. K.; Pattyn, D.; Ares, P.; Goswami, A. Neck-size Distributions of Through-pores in Polymer Membranes. J. Membr. Sci. 2012, 415-416, 608-615.

(43) Gao, L.; Tang, B.; Wu, P. An Experimental Investigation of Evaporation Time and the Relative Humidity on a Novel Positively Charged Ultrafiltration Membrane via Dry-wet Phase Inversion. J. Membr. Sci. 2009, 326 (1), 168-177.

(44) Wang, J.; Zheng, L.; Wu, Z.; Zhang, Y.; Zhang, X. Fabrication of Hydrophobic Flat Sheet and Hollow Fiber Membranes from PVDF and PVDF-CTFE for Membrane Distillation. J. Membr. Sci. 2016, 497, 183-193.

(45) Feng, C.; Khulbe, K. C.; Matsuura, T.; Tabe, S.; Ismail, A. F. Preparation and Characterization of Electro-spun Nanofiber Membranes and Their Possible Applications in Water Treatment. Sep. Purif. Technol. 2013, 102, 118-135.

(46) Tsai, H.; Lin, J.; Wang, D.; Lee, K.; Lai, J. Effect of Vaporinduced Phase Separation on the Morphology and Separation Performance of Polysulfone Hollow Fiber Membranes. Desalination 2006, 200 (1), 247-249.

(47) Khayet, M. The Effects of Air Gap Length on the Internal and External Morphology of Hollow Fiber Membranes. Chem. Eng. Sci. 2003, 58 (14), 3091-3104.

(48) Hou, D.; Fan, H.; Jiang, Q.; Wang, J.; Zhang, X. Preparation and Characterization of PVDF Flat-sheet Membranes for Direct Contact Mmembrane Distillation. Sep. Purif. Technol. 2014, 135, 211-222.

(49) Fan, H.; Peng, Y. Application of PVDF Membranes in Desalination and Comparison of the VMD and DCMD Processes. Chem. Eng. Sci. 2012, 79, 94-102.

(50) Zhang, J.; Li, J. D.; Gray, S. Effect of Applied Pressure on Performance of PTFE Membrane in DCMD. J. Membr. Sci. 2011, 369 (1-2), 514-525.

(51) Lai, C. L.; Liou, R. M.; Chen, S. H.; Huang, G. W.; Lee, K. R. Preparation and Characterization of Plasma-modified PTFE Membrane and its Application in Direct Contact Membrane Distillation. Desalination 2011, 267 (2-3), 184-192.

(52) Feng, C.; Shi, B.; Li, G.; Wu, Y. Preliminary Research on Microporous Membrane from F2. 4 for Membrane Distillation. Sep. Purif. Technol. 2004, 39 (3), 221-228.

(53) Khayet, M.; Cojocaru, C.; García-Payo, M. C. Experimental Design and Optimization of Asymmetric Flat-sheet Membranes Prepared for Direct Contact Membrane Distillation. J. Membr. Sci. 2010, 351 (1-2), 234-245.

(54) Tijing, L. D.; Woo, Y. C.; Johir, M. A. H.; Choi, J. S.; Shon, H. K. A Novel Dual-layer Bicomponent Electrospun Nanofibrous Membrane for Desalination by Direct Contact Membrane Distillation. Chem. Eng. J. 2014, 256, 155-159.

(55) Wei, X.; Zhao, B.; Li, X. M.; Wang, Z.; He, B. Q.; He, T.; Jiang, B. $\mathrm{CF}_{4}$ Plasma Surface Modification of Asymmetric Hydrophilic Polyethersulfone Membranes for Direct Contact Membrane Distillation. J. Membr. Sci. 2012, 407-408, 164-175.

(56) Peng, Y.; Dong, Y.; Fan, H.; Chen, P.; Li, Z.; Jiang, Q. Preparation of Polysulfone Membranes via Vapor-induced Phase Separation and Simulation of Direct Contact Membrane Distillation by measuring hydrophobic layer thickness. Desalination 2013, 316, $53-66$.

(57) Tian, M.; Yin, Y.; Yang, C.; Zhao, B.; Song, J.; Liu, J.; Li, X.-M.; $\mathrm{He}, \mathrm{T} . \mathrm{CF}_{4}$ Plasma Modified Highly Interconnective Porous Polysulfone Membranes for Direct Contact Membrane Distillation (DCMD). Desalination 2015, 369, 105-114. 